\title{
Food safety knowledge of undergraduate students at a Canadian university: results of an online survey
}

Sarah M. Courtney ${ }^{1}$, Shannon E. Majowicz ${ }^{1 *}$ and Joel A. Dubin ${ }^{1,2}$

\begin{abstract}
Background: Foodborne diseases are an important public health issue, and young adults are an important demographic to target with food safety education. Our objective was to assess the food safety knowledge of undergraduate students at a Canadian university, to identify potential areas for such education.

Methods: In February 2015, we conducted an online survey of 485 undergraduate students at a university in Ontario, Canada. We assessed various food-related factors, including cooking frequency and prior food handling or preparation education. We then modeled the relationship between 'overall knowledge score' and the demographic and food skills/cooking experience predictors using multivariable log-binomial regression, to determine factors associated with relatively higher proportions of correct responses.
\end{abstract}

Results: Respondents were, on average, 20.5 years old, and the majority (64.8\%) lived off campus. Students cooked from basic ingredients infrequently, with 3 in 4 doing so a few times a year to never. Students averaged 6.2 correct answers to the 11 knowledge questions. Adjusting for other important covariates, older age and being a current food handler were associated with relatively higher knowledge, whereas working/ volunteering in a hospital and infrequent cooking were associated with relatively lower knowledge. Males in the Faculty of Science had relatively higher knowledge than females in the Faculty of Science, both of whom had relatively higher knowledge than all students in other Faculties. Among students who had never taken a food preparation course, knowledge increased with self-reported cooking ability; however, among students who had taken such a course, knowledge was highest among those with low self-reported cooking ability.

Conclusions: Consistent with other similar studies, students in Faculties outside of the Faculty of Science, younger students, and those who cook infrequently could benefit from food safety education. Supporting improved hand hygiene, in particular clarifying hand washing versus hand sanitizing messages, may also be important. Universities can play a role in such education, including as part of preparing students for work or volunteer placements, or as general support for student health and success.

Keywords: Food safety, Food poisoning, Young adult, Cooking, Food handling, Ontario, Canada

\footnotetext{
*Correspondence: smajowicz@uwaterloo.ca

${ }^{1}$ School of Public Health and Health Systems, University of Waterloo, 200

University Ave. West, Waterloo, Ontario N2L 3G1, Canada

Full list of author information is available at the end of the article
}

(c) The Author(s). 2016 Open Access This article is distributed under the terms of the Creative Commons Attribution 4.0 International License (http://creativecommons.org/licenses/by/4.0/), which permits unrestricted use, distribution, and reproduction in any medium, provided you give appropriate credit to the original author(s) and the source, provide a link to the Creative Commons license, and indicate if changes were made. The Creative Commons Public Domain Dedication waiver (http://creativecommons.org/publicdomain/zero/1.0/) applies to the data made available in this article, unless otherwise stated. 


\section{Background}

Foodborne diseases are an important cause of morbidity and mortality worldwide [1]. In Canada, they cause four million domestically-acquired illnesses each year, affecting one in eight people [2] and costing circa \$364 to $\$ 455$ million [3-6]. Norovirus, Clostridium perfringens, Campylobacter spp., and Salmonella spp. cause the majority of the foodborne illnesses in Canada [2]. In the province of Ontario, the majority are caused by Campylobacter spp., Salmonella spp., and verotoxin-producing E. coli [7], with the greatest population burden linked to Campylobacter spp. and Salmonella spp. infections [8, 9]. The transmission of these and other foodborne pathogens can be prevented via various food safety initiatives along the farm-to-fork continuum, including on-farm pathogen reduction strategies such as livestock vaccination [10], pasteurization of milk during processing [11], and support for proper food handling and hygiene practices by both workers in food service locations (e.g., [12]) and consumers at home (e.g., [13]).

In the home setting, the likelihood that proper food handling and hygiene practices will be used varies by age. Young adults aged 18 and 29 (as well as older adults aged 65 and older) appear more likely to mishandle food than adults of other ages [14-17]. When observed preparing a meal, young adults performed only $50 \%$ of the recommended food safety behaviours [18], and common food hygiene issues observed in this age group include a lack of food thermometers and having refrigerators and freezers at higher-than-recommended temperatures [19], and inadequate hand washing during food handling [20]. Food mishandling and improper food hygiene practices by young adults may contribute, in part, to the increased incidence of both acute gastrointestinal illness [21] and foodborne disease [22], and the relative increase in the reporting of suspected food poisoning [23], that has been observed in this demographic. Hypothesized reasons for young adults' poor food handling practices relate to insufficient opportunities for learning safe food handling, including because of increasing consumption of already prepared foods [24], and fewer home economics or other types of food handling and preparation classes in public schools [25]. In addition, many young adults have never held employment involving preparing or serving food, do not possess food safety certification, and have not completed a college course in nutrition, food science, or microbiology [25].

Most assessments of consumer food safety include a measurement of the food safety knowledge of the population of interest. For young adults, food safety knowledge has primarily been investigated in college and university students. Although different study years, populations, and knowledge measurement tools make direct comparisons between studies difficult, most have found that students do not possess the appropriate food safety knowledge to protect themselves from foodborne disease (albeit with better knowledge among students with a health or similar major), as follows. Among students at various United States' (U.S.) colleges, the average percentage of correct answers to food safety knowledge questions has been measured at $49 \%$ (10.3 correct answers out of 21 questions; health majors [26]), and $60 \%$ (53 out of 89 [27]; and [25]). Knowledge appears to vary by major, for example from an average of $64 \%$ correct answers (12.11 out of 19) for engineering majors to $76 \%$ (14.41 out of 19) for dietetics majors [28], and from $73 \%$ correct answers (10.2 out of 14) for non-health majors, to $84 \%$ (11.8 out of 14) for health majors [29]. Another study, which did not report overall knowledge, found that knowledge varied by question, from $17 \%$ of students knowing the proper temperature for reheating leftovers, to $82 \%$ knowing leftovers should be refrigerated within $2 \mathrm{~h}$ [30].

Food safety knowledge also appears to be inadequate among university students outside of the U.S. For example, both female students in Jordan (37.39 out of 81 [31]) and Greek students (6 out of 13 [32]) averaged $46 \%$ correct answers to food safety knowledge questions, while Lebanese students averaged $54 \%$ correct answers [33], and students in Turkey averaged $57 \%$ (11.97 out of 21 [34]). Students in Saudi Arabia averaged $75 \%$ correct answers to 15 knowledge questions [35]. A study of Spanish health sciences students, that did not report overall knowledge, found $50 \%$ of students knew to wash utensils used on raw product before cutting cooked products, and that $85 \%$ knew to wash hands before, during, and after food manipulation [36].

In Canada, food safety among young adults is not well understood, with no studies examining food safety among university students (nor other young adult populations). In Ontario, one recent study in high school students found food safety knowledge, attitudes, and self-reported practices to be poor in this age group [37], and another found that young adults generally have poorer food safety knowledge than other older adults [15]. Given the potential importance of young adults as a demographic to target with food safety education, and that university settings may offer opportunities to provide such education (e.g., via content in relevant academic courses, training prior to co-operative education placements, or within residences or dormitories), the objective of our study was to assess the food safety knowledge of undergraduate students at a Canadian university, including demographic factors associated with food safety knowledge, in order to identify areas for, and groups that may benefit from, possible food safety education. 


\section{Methods}

In February 2015, we administered an electronic, crosssectional survey to undergraduate students at the University of Waterloo, a public research university with a population of $\sim 30,000$ undergraduate and $\sim 5500$ postgraduate students, located in the City of Waterloo, Ontario, Canada (population 99,000). Using a random number generator, a sub-set of 5000 undergraduate students was selected, using simple random sampling, from the 29,440 active undergraduate students enrolled at the time of the study. This sub-set size was chosen assuming a $10 \%$ response rate, to yield a final target sample size of 500 participants; the sample size was calculated to detect an anticipated difference in the mean number of correct food safety knowledge questions between males and females of 6.5 and 7.0 correct answers out of 11 (s.d. 2.5), with a type I error of 0.05 and a power of 0.80 .

An email requesting student participation and containing the link to the survey was sent to the 5000 students by the University's Registrar's Office on February 26, 2015. The email provided details about the study and included the researchers' contact information. A reminder email was sent to all 5000 students by the University's Registrar's Office, with the exception of those who explicitly requested no further contact about the study, eight days following the initial invitation.

The electronic survey was conducted in the online platform 'Hosted in Canada Surveys' (http://www.hostedincanadasurveys.ca). The survey was open for participation from February 26 to March 12, 2015. On the first page of the web survey, students were again provided study details (including their right to discontinue participating at any time), and students gave informed consent before proceeding to the survey questions. In return for their participation, students had the option to provide an email address to be entered into a draw to win one of four $\$ 50$ gift cards, to a location of their choice (e.g., gas station, book store). The email addresses were captured in a separate file from the survey data and could not be used to link an email address to an individual's answers. This study was reviewed and received ethics clearance through a University of Waterloo Research Ethics Committee.

Our questionnaire was a modified version of one previously used to assess food safety in Ontario high school students [37]. Briefly, the original questionnaire was developed by selecting questions from existing, validated questionnaires that assessed, among other items, food safety knowledge across a variety of areas such as hand hygiene, cooking temperatures, and food storage [29, 38-41]. We modified the wording to include 'undergraduate' instead of 'high school', adjusted response options to be relevant (e.g., included older age categories), and added some undergraduate-specific items such as whether students lived in residence or off campus, and to which Faculty within the University they belonged. The questionnaire (Additional file 1) was designed to take approximately $15 \mathrm{~min}$ to complete, and contained a range of questions related to food safety. Questions analysed for this study were the 5 demographic questions, the 5 food skills and cooking experience questions, the 11 food safety knowledge questions for which a correct answer exists (e.g., "what is the most hygienic way to wash your hands?"), and the 1 food safety knowledge question for which correct answers are more nuanced ("where do you think food safety problems are most likely to occur?"). All questions were multiple-choice format, and for one question ("where do you think food safety problems are most likely to occur?") more than one answer could be selected.

Data were analysed in Stata/SE 14.0 for Mac (StataCorp LP, College Station, Texas). Because missing data were infrequent across all questions (see Results), they were omitted from the analysis of each given question. Differences between demographic characteristics of the study participants versus the overall undergraduate student body were tested using t-tests (for mean ages), and Pearson's chi-square test, and Fisher's exact test if necessary (for proportions per sex, Faculty, and co-op versus regular system of study). To compare the average age of study participants to the overall undergraduate population, we used 'study year' (available for the undergraduate student body in lieu of age) as a proxy, assuming first year students were 18 years old, second year students were 19 years old, and so on, at the time of the study. Pairwise correlations between correct answers to the 11 individual knowledge questions were calculated.

We assessed the demographic and food skills/cooking experience factors as predictors of responses to the individual knowledge items, using multivariable logistic regression. We included all predictor variables in each model, collapsing multiple-level variables to fewer categories if necessary to avoid empty cells. We then modeled the relationship between the dependent variable 'overall knowledge score' (out of 11) and the demographic and food skills/cooking experience predictors using multivariable log-binomial regression. Log-binomial models can be used to estimate prevalence ratios [42-44], for example the relative prevalence of a disease in men versus women; here, we used a log-binomial model to assess the relative proportion of correct answers, out of 11, across levels of our predictor variables. We first started with the full model that included all predictors significantly associated with at least one individual knowledge item, and the 11 two-way interactions between these predictors we hypothesized a priori as being plausible (age by current living arrangement; sex by faculty; self-described cooking ability by current food handler status, previous training, 
currently working/volunteering in a food service location, frequency of cooking from basic ingredients, and current living arrangement; previous training by current food handler status, and currently working/volunteering in a food service location; current living arrangement by frequency of cooking from basic ingredients; and food handler status by currently working/volunteering in a food service location). We included age as a linear term (based on a graphical examination of the relationship between age and overall knowledge score). To avoid empty cells, for the variable 'cooking ability', we merged the two smallest categories, that were the two lowest cooking abilities ('don't know how to cook' and 'can only cook food when the instructions are on the box'), and for the variable 'cooking frequency', we merged the three smallest categories, that were the three most frequent ('a few times a month', 'a few times a week', and 'at least once a day'). Any non-significant interaction terms were removed from the model. We then removed all non-significant predictors from the model (retaining any non-significant main effects of significant interaction terms), and assessed each removed variable for potential confounding by re-introducing it to the model, examining any changes in sign, significance, or magnitude of the other model predictors, and retaining any non-significant predictors that had such impacts. For all regression models, because we hypothesized that students within any particular area of study (e.g., within Science, or Arts) might be more similar with respect to food safety knowledge (e.g., due to course content), we adjusted for non-independence of students within the six Faculties using the clustered sandwich estimator of variance [45].

\section{Results}

In total, 491 students completed the survey, yielding a response rate $(9.8 \%)$ very close to the expected response rate $(10 \%) ; 6$ surveys were missing the majority of question responses, resulting in a final sample of 485 participants. Missing data were infrequent; the variable with the most missing data ("have you ever taken a course where you were taught how to prepare food...") was $95.3 \%$ complete (462/485); details of all variables with missing data are given in Additional file 2. Demographic characteristics of survey respondents, the invited sample, and the undergraduate student body of the University are shown in Table 1. Overall, there were more females and

Table 1 Demographic characteristics of study participants, the invited sample, and the University of Waterloo undergraduate population, 2015

\begin{tabular}{|c|c|c|c|c|}
\hline \multirow[t]{2}{*}{ Demographic Characteristic } & \multicolumn{2}{|c|}{ Study participants $(n=485)$} & \multirow{2}{*}{$\begin{array}{l}\text { Invited sample }(n=5000) \\
\text { Percent (number) }\end{array}$} & \multirow{2}{*}{$\begin{array}{l}\text { Undergraduate population }(n=29,440) \\
\text { Percent }\end{array}$} \\
\hline & Percent (number) & $95 \%$ C.I. $^{a}$ & & \\
\hline \multicolumn{5}{|l|}{ Gender } \\
\hline Male & $35.0(167)$ & $(30.8,39.4)$ & $55.1(2755)$ & 54.5 \\
\hline Female & $65.0(310)$ & $(60.6,69.2)$ & $44.9(2245)$ & 45.5 \\
\hline \multicolumn{5}{|l|}{ Faculty } \\
\hline Applied Health Sciences & $10.2(49)$ & $(7.8,13.3)$ & $8.1(405)$ & 7.2 \\
\hline Arts & $20.0(96)$ & $(16.6,23.8)$ & $21.4(1070)$ & 21.9 \\
\hline Engineering & $23.1(111)$ & $(19.6,27.1)$ & $22.3(1115)$ & 22.3 \\
\hline Environment & $8.8(42)$ & $(6.5,11.6)$ & $6.8(340)$ & 7.5 \\
\hline Mathematics & $14.6(70)$ & $(11.7,18.0)$ & $21.6(1080)$ & 21.3 \\
\hline Science & $23.3(112)$ & $(19.8,27.3)$ & $16.8(840)$ & 17.0 \\
\hline Other & - & - & $3.0(150)$ & 2.8 \\
\hline \multicolumn{5}{|l|}{ System of study } \\
\hline Co-op & $63.1(301)$ & $(58.7,67.3)$ & $62.2(3110)$ & 62.2 \\
\hline Regular & $36.9(176)$ & $(32.7,41.3)$ & $37.8(1890)$ & 37.8 \\
\hline \multicolumn{5}{|l|}{ Study year } \\
\hline First & - & - & $21.2(1060)$ & 22.5 \\
\hline Second & - & - & 26.3 (1315) & 26.6 \\
\hline Third & - & - & $25.3(1265)$ & 24.1 \\
\hline Fourth & - & - & 24.1 (1205) & 24.0 \\
\hline Fifth & - & - & $0.3(15)$ & 0.3 \\
\hline Non-degree & - & - & $2.8(140)$ & 2.4 \\
\hline
\end{tabular}

${ }^{a}$ Significant differences between study participants and the undergraduate student body are shown in bold 
students from the Faculties of Applied Health Sciences and Science, and fewer males and students from the Faculty of Mathematics, in the participating sample of students versus the undergraduate student body as a whole. The average age of study participants (20.5 years; $95 \%$ Confidence Interval [C.I.]: 20.3, 20.6) was slightly older than the approximated average age of the undergraduate student body $(19.6$ years; $p<0.0001)$. The majority of participants lived off campus (64.8\%; 311/480), followed by living at home (17.5 \%; 84/480), and living in traditional-style $(10.6 \% ; 51 / 480)$ and suite-style (7.1\%; 34/480) residences; similar data were not available for the undergraduate population.

Overall, $10.1 \%(49 / 485)$ of respondents worked or volunteered in a restaurant, deli, or other food service location; $8.5 \%(41 / 485)$ in a daycare or other place where they interact with children; $6.2 \%(30 / 485)$ in a hospital; and $1.9 \%(9 / 485)$ in a retirement home, nursing home, or long-term care facility. Handling food was not limited to respondents working or volunteering in a restaurant, deli, or other food service location, although these respondents were predominantly food handlers $(87.8 \%$; 43/49). Food handling for the public also occurred by those working or volunteering in a retirement home or long-term care facility $(44.4 \% ; 4 / 9)$; a day care or other location for children (29.3\%; 12/41); or in a hospital (16.7\%; 5/30). Overall, 1 in 10 (10.6\%; 51/485) respondents reported currently handling food in commercial or public-serving venues. Roughly 2 in 5 respondents $(39.2 \%$; 190/485) had ever taken a course where they were taught to prepare food, such as a high school food and nutrition class, or food handler certification. Such courses were no more nor less frequent among those currently handling food for the public $(43.1 \%$; $22 / 51)$ compared to those not doing so (38.2\%; $166 /$ $434 ; p=0.653)$.

Students cooked from basic ingredients infrequently, with most doing so a few times a year $(40.7 \%$; 195/479) or never $(34.2 \% ; 164 / 479)$, followed by a few times a month (16.7\%; 80/479), a few times a week (4.4\%; $21 / 479)$, and at least once a day $(4.0 \% ; 19 / 479)$. Selfreported cooking ability was advanced, with most students reporting they can "prepare simple meals if I have a recipe to follow" (50.6\%; 243/480), or "cook almost anything" (39.8 \%; 191/480). Relatively fewer students reported they "can do the basics from scratch (like boil an egg or make a grilled cheese sandwich) but nothing more complicated" $(6.7 \% ; 32 / 480)$, or "can only cook food when the instructions are on the box" $(2.3 \% ; 11 / 480)$, and less than one percent felt they "don't know how to cook" $(0.6 \% ; 3 / 480)$.

When asked where they thought food safety problems were most likely to occur, $5.0 \%(24 / 485)$ indicated they did not know. The remaining respondents selected homes
(70.9 \%; 327/461), followed by restaurants (64.6\%; 298/461), food processing plants (52.9\%; 244/461), supermarkets (42.7\%; 197/461), warehouses (40.4\%; $186 / 461)$, and farms $(31.7 \% ; 146 / 461)$. Most respondents selected one $(25.2 \% ; 116 / 461)$, two $(19.1 \%$; 88/461), or three $(19.5 \%$; $91 / 461)$ of the possible answers. Associations between the predictor variables and the selection of these items is shown in Table 2.

The knowledge question for which the correct answer was selected most frequently was the description of microorganisms (Table 3); interestingly, although most incorrect answers related to a possible increase in foodborne disease risk (e.g., cutting meat open in lieu of using a food thermometer), one incorrect answer (storing leftovers for 1-2 days, instead of 3-4 days) did not. Relationships between the predictor variables and correct answers for the 11 knowledge questions are shown in Tables 4 and 5; working or volunteering in a long-term care or retirement facility was the only variable not associated with a correct answer for any of the knowledge questions. No knowledge questions had correct answers perfectly predicted by, or nested within, other answers. All pairwise correlations between correct responses for the individual knowledge questions were less than or equal to 0.170 . Knowing that a food thermometer is the best way to check hamburger doneness was correlated with knowing how long leftover foods should be heated $(r=0.168 ; 95 \%$ C.I. $0.075,0.248)$, and what to do with accidentally thawed meat $(r=0.163$; $95 \%$ C.I. $0.081,0.253)$. What to do with accidentally thawed meat was also correlated with knowing how to safely store a hot meal to be eaten several hours later $(r=$ 0.170; 95 \% C.I. 0.083, 0.255).

Participants averaged 6.2 (s.d. $=1.79 ; \min =1, \max =$ 11; median =6) correct answers to the 11 knowledge questions. The final multivariable log-binomial regression model, showing adjusted prevalence ratios for significant predictors, is given in Table 6. Two factors were associated with a relatively higher knowledge score; adjusting for the other model variables, for each additional year of age, the estimated proportion of correct answers was 1.02 greater, and the estimated proportion of correct answers was 1.11 times higher in students who were current food handlers than those who were not. Two factors were associated with relatively lower knowledge scores; adjusting for the other model variables, the estimated proportion of correct answers was 1.09 times lower (95 \% C.I. 1.00, 1.19; $p=0.040$; i.e., 0.92 times higher) in students who worked or volunteered in a hospital than those who did not, and the estimated proportion of correct answers was 1.05 times lower (95 \% C.I. 1.00, 1.10; $p=0.033$; i.e., 0.95 times higher) in students who reported cooking only a few times a year, versus those who never cook. 
Table 2 Odds ratios (and $95 \%$ Confidence Intervals), for demographic and food skills predictors of answers selected in response to the question "where do you think food safety problems are most likely to occur", among those not indicating 'I don't know' $(n=418)$; significant predictors are shown in bold

\begin{tabular}{|c|c|c|c|c|c|c|}
\hline & Homes & Restaurants & $\begin{array}{l}\text { Food processing } \\
\text { plants }\end{array}$ & Super-markets & Warehouses & Farms \\
\hline Age (in years) & $1.18(1.00,1.40)$ & $1.01(0.84,1.22)$ & $1.04(0.83,1.30)$ & $0.94(0.79,1.10)$ & $0.86(0.78,0.95)$ & $1.03(0.89,1.18)$ \\
\hline Male sex (female = referent) & $1.45(0.83,2.55)$ & $0.65(0.42,1.01)$ & $0.68(0.36,1.28)$ & $0.92(0.69,1.24)$ & $0.90(0.70,1.14)$ & $0.68(0.37,1.26)$ \\
\hline \multicolumn{7}{|l|}{ Faculty } \\
\hline Science & referent & & & & & \\
\hline Applied Health Sciences & $0.72(0.58,0.89)$ & $0.56(0.49,0.63)$ & $1.38(1.16,1.63)$ & $1.39(1.24,1.57)$ & $1.07(0.98,1.18)$ & $1.00(0.81,1.25)$ \\
\hline Arts & $0.83(0.75,0.89)$ & $0.88(0.81,0.95)$ & $0.98(0.79,1.20)$ & $0.84(0.77,0.92)$ & $1.07(0.98,1.16)$ & $0.73(0.64,0.83$ \\
\hline Engineering & $0.95(0.68,1.33)$ & $1.02(0.79,1.32)$ & $1.05(0.76,1.44)$ & $0.55(0.46,0.65)$ & $0.66(0.52,0.86)$ & $0.47(0.31,0.70$ \\
\hline Environment & $0.81(0.71,0.94)$ & $0.93(0.69,1.23)$ & $1.53(1.22,1.92)$ & $1.31(1.03,1.68)$ & $1.25(0.95,1.65)$ & $0.63(0.41,0.96$ \\
\hline Mathematics & $0.67(0.50,0.90)$ & $0.67(0.54,0.83)$ & $0.89(0.63,1.26)$ & $0.97(0.77,1.19)$ & $0.50(0.40,0.62)$ & $0.64(0.50,0.83$ \\
\hline $\begin{array}{l}\text { Co-op program of study } \\
\text { (regular program = referent) }\end{array}$ & $1.21(0.64,2.28)$ & $0.94(0.62,1.41)$ & $0.76(0.55,1.04)$ & $1.12(0.89,1.41)$ & $1.19(0.82,1.72)$ & $1.15(0.70,1.91)$ \\
\hline Is a current food handler & $0.50(0.10,2.45)$ & $1.44(0.37,5.62)$ & $1.70(0.40,7.33)$ & $4.72(3.02,7.35)$ & $5.98(1.79,20.0)$ & $0.89(0.21,3.72)$ \\
\hline \multicolumn{7}{|l|}{ Works or volunteers in a... } \\
\hline ...food service location & $3.26(0.57,18.6)$ & $1.78(0.12,25.3)$ & $0.52(0.23,1.16)$ & $0.18(0.04,0.78)$ & $0.14(0.02,0.71)$ & $1.10(0.47,2.59)$ \\
\hline ...hospital & $2.25(1.80,2.81)$ & $2.26(0.62,8.25)$ & $1.14(0.36,3.62)$ & $1.23(0.87,1.74)$ & $0.83(0.55,1.24)$ & $1.22(0.81,1.85)$ \\
\hline ...daycare/child care facility & $1.39(0.47,4.05)$ & $0.57(0.24,1.33)$ & $1.13(0.34,3.72)$ & $0.37(0.20,0.71)$ & $0.66(0.44,1.00)$ & $0.64(0.35,1.17)$ \\
\hline $\begin{array}{l}\text {...long-term care/retirement } \\
\text { home facility }\end{array}$ & $2.87(0.16,52.7)$ & $\begin{array}{l}\text { omitted due to } \\
\text { co-linearity }\end{array}$ & $0.33(0.11,0.97)$ & $0.55(0.10,2.91)$ & $0.93(0.27,3.24)$ & $0.23(0.01,4.41)$ \\
\hline $\begin{array}{l}\text { Has ever taken a previous food } \\
\text { course }\end{array}$ & $1.61(1.06,2.45)$ & $1.05(0.67,1.57)$ & $0.78(0.33,1.85)$ & $1.18(0.72,1.94)$ & $0.74(0.40,1.35)$ & $0.97(0.64,1.47)$ \\
\hline
\end{tabular}

Current living arrangement

Living at home
Traditional-style residence
Suite-style residence
Living off campus

referent

$\begin{array}{llllll}0.58(0.27,1.25) & 1.01(0.57,1.77) & 1.01(0.51,2.00) & 0.65(0.26,1.62) & 0.78(0.42,1.46) & 1.21(0.40,3.62) \\ 0.67(0.24,1.87) & \mathbf{2 . 1 0 ( 1 . 1 1 , ~ 3 . 9 5 )} & 1.75(0.98,3.11) & 0.96(0.63,1.47) & 0.77(0.27,2.21) & 2.30(0.79,6.74) \\ 0.74(0.50,1.09) & \mathbf{1 . 5 6 ( 1 . 0 7 , ~ 2 . 2 7 )} & 0.89(0.61,1.30) & 1.01(0.55,1.86) & 1.02(0.64,1.63) & 1.09(0.41,2.91)\end{array}$

Frequency of cooking from basic ingredients

\section{Never or a few times a year \\ A few times a month \\ A few times a week or more}

Good self-described cooking ability ${ }^{a}$ referent

\begin{tabular}{llllll}
$\mathbf{0 . 4 8}(\mathbf{0 . 2 5}, \mathbf{0 . 9 4})$ & $0.97(0.51,1.82)$ & $1.69(0.68,4.21)$ & $0.65(0.26,1.62)$ & $1.45(0.78,2.68)$ & $1.27(0.69,2.32)$ \\
$1.15(0.49,2.69)$ & $1.21(0.54,2.67)$ & $\mathbf{0 . 5 4}(\mathbf{0 . 3 1} \mathbf{0 . 9 4})$ & $0.96(0.63,1.47)$ & $1.40(0.60,3.25)$ & $0.84(0.27,2.63)$ \\
$1.19(0.49,2.69)$ & $0.94(0.57,1.57)$ & $0.67(0.34,1.32)$ & $1.31(0.92,1.86)$ & $0.78(0.37,1.63)$ & $0.96(0.35,2.62)$ \\
\hline
\end{tabular}

${ }^{a}$ Those reporting the ability to cook the basics from scratch, prepare simple meals from a recipe, or cook almost anything (referent: those reporting they don't know how to cook, or that they can only cook food when the instructions are on the box)

There was a significant interaction between being in the Faculty of Science and being male (Fig. 1). Adjusting for the other model variables, the estimated proportion of correct answers was 1.16 (95\% C.I. 1.04, 1.29; $p<$ 0.001 ) and 1.06 times higher (95\% C.I. 1.04, 1.07; $p<$ 0.001 ) for males and females in the Faculty of Science, respectively, compared to females in the other Faculties, although the proportions of correct answers for males and for females in other Faculties were similar. There was also a significant interaction between self-reported cooking ability and whether or not the student had ever taken a course in which they were taught to prepare or handle food (Fig. 2). Adjusting for the other model variables, in students who had never taken a previous course, the proportion of correct answers increased as self-reported cooking ability increased, such that the estimated proportion of correct answers was 1.44 times higher $(95 \%$ C.I. 1.18, 1.76; $p<0.001$ ) for those who reported they 'can cook almost anything' versus those who reported they don't know how to cook or can only cook 'when the instructions are on the box'. Among students who had taken a course in which they had been taught to prepare or handle food, the estimated proportion of correct answers was highest 
Table 3 Percent of University of Waterloo undergraduate student respondents $(n=485)$ selecting the correct answer, and the most frequently selected incorrect answer, to food safety knowledge questions

\begin{tabular}{|c|c|c|c|c|}
\hline \multirow[t]{2}{*}{ Question } & \multicolumn{4}{|c|}{ Percent of Students Selecting a Given Answer } \\
\hline & Correct Answer & $\%$ & Most Frequent Incorrect Answer & $\%$ \\
\hline What are microorganisms? & $\begin{array}{l}\text { Small living things that are too small } \\
\text { to be seen with our eyes }\end{array}$ & 96.8 & $\begin{array}{l}\text { Poisons that can contaminate our } \\
\text { food and water }\end{array}$ & 2.3 \\
\hline $\begin{array}{l}\text { Which of the following is considered the } \\
\text { most important way to prevent food poisoning? }\end{array}$ & $\begin{array}{l}\text { Keep foods refrigerated until it's time } \\
\text { to cook or serve them }\end{array}$ & 84.3 & $\begin{array}{l}\text { Clean kitchen counters with } \\
\text { sanitizing solutions weekly }\end{array}$ & 11.7 \\
\hline Chilling or freezing eliminates harmful germs & False & 77.0 & True & 23.0 \\
\hline Which is the most hygienic way to wash your hands? & $\begin{array}{l}\text { Run water, moisten hands, apply } \\
\text { soap, rub hands together for } 20 \text { s, } \\
\text { rinse hands, dry hands }\end{array}$ & 71.5 & $\begin{array}{l}\text { Apply soap, rub hands together for } \\
20 \text { s, rinse hands under water, dry } \\
\text { hands, apply sanitizer }\end{array}$ & 15.4 \\
\hline $\begin{array}{l}\text { If a family member is going to be several hours late } \\
\text { for a hot meal, how should you store the meal to } \\
\text { keep it safe until this person is ready to eat it? }\end{array}$ & $\begin{array}{l}\text { Store it in the refrigerator and reheat } \\
\text { it when the person is ready to eat it }\end{array}$ & 65.7 & $\begin{array}{l}\text { Store it a warm oven until the } \\
\text { person is ready to eat it }\end{array}$ & 26.9 \\
\hline $\begin{array}{l}\text { Imagine your electricity went off and the meat, } \\
\text { chicken, and/or seafood in your freezer thawed and } \\
\text { felt warm. What should you do? }\end{array}$ & Throw them away & 56.0 & $\begin{array}{l}\text { See how they smell or look before } \\
\text { deciding what to do }\end{array}$ & 30.1 \\
\hline $\begin{array}{l}\text { Which method is the best way of determining } \\
\text { whether hamburgers are cooked enough? }\end{array}$ & $\begin{array}{l}\text { Measure the temperature with a } \\
\text { food thermometer }\end{array}$ & 51.4 & $\begin{array}{l}\text { Cut one to check the colour of the } \\
\text { meat inside }\end{array}$ & 35.4 \\
\hline $\begin{array}{l}\text { How long should leftovers be stored in the } \\
\text { refrigerator? }\end{array}$ & $3-4$ days & 37.2 & $1-2$ days & 36.3 \\
\hline $\begin{array}{l}\text { All foods (except whole poultry) are considered } \\
\text { safe when cooked to an internal temperature of: }\end{array}$ & $165^{\circ} \mathrm{F}\left(74^{\circ} \mathrm{C}\right)$ & 41.6 & $150^{\circ} \mathrm{F}\left(66^{\circ} \mathrm{C}\right)$ & 31.0 \\
\hline $\begin{array}{l}\text { To prevent food poisoning, how long should leftover } \\
\text { foods be heated? }\end{array}$ & Until they are boiling hot & 31.8 & $\begin{array}{l}\text { Just until they are hot, but not too } \\
\text { hot to eat right away }\end{array}$ & 43.4 \\
\hline $\begin{array}{l}\text { Which procedure for cleaning kitchen counter } \\
\text { is best? }\end{array}$ & $\begin{array}{l}\text { Wash with a detergent, rinse, then } \\
\text { wipe with a sanitizing solution }\end{array}$ & 24.0 & $\begin{array}{l}\text { Wipe with a sanitizing solution, then } \\
\text { rinse with clean water and wipe dry }\end{array}$ & 44.2 \\
\hline
\end{tabular}

among those who reported they don't know how to cook or can only cook 'when the instructions are on the box'.

\section{Discussion}

We conducted an online survey of the food safety knowledge of undergraduate students at the University of Waterloo, a public research university with a population of $\sim 30,000$ undergraduate students located in Ontario, Canada. Overall, we found knowledge to be poor, and generally comparable to that of other college and university students worldwide (Table 7); knowledge was slightly higher, however, than that of high school students (who averaged $47 \%$ correct responses), measured during the same time frame and in the same province [37]. In this study, our university students answered an average of $56 \%$ of the knowledge questions correctly. For all but one question (leftovers, discussed below), the most frequently selected incorrect answer related to an increased foodborne disease risk. That students' inaccurate food safety knowledge may increase foodborne disease risk is important, because although students reported cooking from basic ingredients infrequently (with 3 in 4 students reporting cooking only a few times a year or never), the majority (65\%) lived off-campus and presumably handled food for their own consumption in some capacity. As well, 1 in
10 students reported currently handling food for the public (including via working or volunteering in food service premises, day cares, long-term care facilities, and hospitals). Although those currently handling food did provide relatively more correct answers than did nonfood handlers, the types of correct answers more frequent among food handlers pertained to refrigeration, thawing, and cleaning counters. Food handlers were no more knowledgeable about other food safety items, including correct hand washing and thermometer use, and thus still may represent a potential risk to others.

Here, roughly $70 \%$ of students knew the correct way to wash hands, which is higher than has been previously reported in other college/university populations where studies have used the same survey question (Table 7). Of concern, however, is that those working or volunteering in a hospital, as well as those living in residence or off-campus, were half as likely to know the correct way to wash hands (versus those not working/volunteering in a hospital, and those living at home, respectively), adjusting for all other factors considered. The incorrect options for the hand washing multiple-choice question all involved the use of hand sanitizers. That students selected options with sanitizers, including sanitizer use without soap and water, suggests that students may not understand the mechanics and purpose of hand washing versus hand 
Table 4 Odds ratios (and $95 \%$ Confidence Intervals), for demographic and food skills predictors of correct answers for individual food safety knowledge questions, answered correctly by more than $50 \%$ of respondents $(n=485)$; significant predictors are shown in bold

\begin{tabular}{|c|c|c|c|c|c|c|c|}
\hline & Defining Micro-organism ${ }^{a}$ & $\begin{array}{l}\text { Preventing Food } \\
\text { Poisoning }\end{array}$ & Chilling/Freezing ${ }^{c}$ & Hand Washing $^{\mathrm{d}}$ & $\begin{array}{l}\text { Storing Meals to } \\
\text { Eat Later }^{\mathrm{e}}\end{array}$ & $\begin{array}{l}\text { Accidental Freezer } \\
\text { Thawing }^{\dagger}\end{array}$ & $\begin{array}{l}\text { Determining Burger } \\
\text { Doneness }{ }^{9}\end{array}$ \\
\hline Age (in years) & $0.95(0.73,1.24)$ & $1.01(0.83,1.22)$ & $1.13(0.96,1.33)$ & $1.01(0.91,1.12)$ & $0.98(0.75,1.28)$ & $1.05(0.91,1.21)$ & $1.11(0.92,1.34)$ \\
\hline Male sex $($ female $=$ referent $)$ & $2.21(1.47,3.32)$ & $1.05(0.68,1.63)$ & $1.04(0.52,2.05)$ & $0.95(0.61,1.50)$ & $1.68(0.87,3.24)$ & $1.05(0.62,1.77)$ & $0.70(0.40,1.25)$ \\
\hline \multicolumn{8}{|l|}{ Faculty } \\
\hline Science & referent & & & & & & \\
\hline Applied Health Sciences & $0.17(0.087,0.33)$ & $6.96(4.95,9.79)$ & $0.70(0.50,0.98)$ & $0.75(0.59,0.95)$ & $0.73(0.51,1.04)$ & $0.71(0.62,0.81)$ & $1.15(0.82,1.61)$ \\
\hline Arts & $0.08(0.59,1.01)$ & $1.27(0.98,1.64)$ & $0.89(0.80,0.98)$ & $0.53(0.47,0.60)$ & $2.34(2.00,2.74)$ & $1.24(1.12,1.37)$ & $0.76(0.63,0.92)$ \\
\hline Engineering & $0.12(0.04,0.37)$ & $0.57(0.29,1.11)$ & $0.88(0.54,1.41)$ & $0.56(0.35,0.91)$ & $0.65(0.46,0.91)$ & $0.56(0.45,0.69)$ & $0.83(0.60,1.15)$ \\
\hline Environment & $0.36(0.14,0.92)$ & $1.24(0.98,1.57)$ & $0.97(0.77,1.22)$ & $0.76(0.68,0.86)$ & $1.63(1.24,2.15)$ & $0.91(0.77,1.07)$ & $1.25(0.88,1.78)$ \\
\hline Mathematics & $0.17(0.08,0.37)$ & $0.92(0.56,1.51)$ & $1.17(0.88,1.57)$ & $0.33(0.23,0.46)$ & $0.51(0.37,0.70)$ & $0.65(0.56,0.76)$ & $1.17(1.01,1.35)$ \\
\hline $\begin{array}{l}\text { Co-op program of study (regular } \\
\text { program = referent) }\end{array}$ & $1.12(0.23,5.34)$ & $0.97(0.35,2.68)$ & $1.05(0.55,2.00)$ & $0.77(0.34,1.71)$ & $1.26(0.86,1.84)$ & $1.08(0.77,1.51)$ & $1.26(0.82,1.94)$ \\
\hline Is a current food handler & $4.57(0.10,215)$ & $5.41(1.94,15.1)$ & $0.48(0.12,1.89)$ & $3.22(0.81,12.7)$ & $0.52(0.19,1.45)$ & $3.73(1.91,7.30)$ & $0.58(0.14,2.38)$ \\
\hline \multicolumn{8}{|l|}{ Works or volunteers in a... } \\
\hline $\begin{array}{l}\text {... restaurant or other food } \\
\text { service location }\end{array}$ & $0.23(0.001,41.1)$ & $0.20(0.03,1.27)$ & $3.64(0.46,28.8)$ & $0.565(0.17,1.79)$ & $0.80(0.45,1.44)$ & $0.83(0.31,2.17)$ & $2.78(0.25,30.5)$ \\
\hline ...hospital & $0.46(0.05,4.14)$ & $0.93(0.14,6.20)$ & $0.65(0.36,1.20)$ & $0.41(0.27,0.63)$ & $0.95(0.33,2.75)$ & $0.99(0.61,1.61)$ & $0.91(0.43,1.91)$ \\
\hline ...daycare/child care facility & $0.27(0.11,0.67)$ & $0.64(0.23,1.77)$ & $0.72(0.25,2.07)$ & $0.74(0.27,1.98)$ & $1.82(0.74,4.49)$ & $0.88(0.41,1.90)$ & $0.77(0.30,1.97)$ \\
\hline $\begin{array}{l}\text {...long-term care/retirement } \\
\text { home facility }\end{array}$ & omitted due to co-linearity & $1.10(0.10,12.3)$ & $2.97(0.30,29.9)$ & $2.378(0.50,11.4)$ & $2.53(0.49,12.9)$ & $1.53(0.23,10.1)$ & $1.33(0.17,10.5)$ \\
\hline $\begin{array}{l}\text { Has ever taken a previous } \\
\text { food course }\end{array}$ & $1.71(0.53,5.54)$ & $1.20(0.65,2.24)$ & $1.22(0.73,2.04)$ & $0.94(0.46,1.92)$ & $1.60(1.09,2.36)$ & $0.71(0.48,1.05)$ & $1.45(0.98,2.15)$ \\
\hline \multicolumn{8}{|l|}{ Current living arrangement } \\
\hline Living at home & referent & & & & & & \\
\hline Traditional-style residence & $1.03(0.24,4.43)$ & $0.85(0.30,2.41)$ & $0.84(0.38,1.86)$ & $0.49(0.27,0.88)$ & $0.75(0.33,1.71)$ & $1.17(0.37,3.71)$ & $1.46(0.78,2.71)$ \\
\hline Suite-style residence & $1.26(0.11,15.1)$ & $0.24(0.06,1.01)$ & $0.62(0.24,1.60)$ & $1.24(0.52,2.95)$ & $0.38(0.18,0.87)$ & $0.52(0.28,0.96)$ & $1.43(0.60,3.42)$ \\
\hline Living off campus & $0.92(0.21,4.10)$ & $0.71(0.28,1.76)$ & $0.78(0.48,1.26)$ & $0.60(0.41,0.87)$ & $0.64(0.40,1.03)$ & $0.77(0.60,1.00)$ & $0.72(0.31,1.68)$ \\
\hline
\end{tabular}


Table 4 Odds ratios (and $95 \%$ Confidence Intervals), for demographic and food skills predictors of correct answers for individual food safety knowledge questions, answered correctly by more than $50 \%$ of respondents $(n=485)$; significant predictors are shown in bold (Continued)

\begin{tabular}{|c|c|c|c|c|c|c|c|}
\hline A few times a month & $0.44(0.21,0.90)$ & $0.65(0.30,1.43)$ & $0.62(0.30,1.29)$ & $0.86(0.63,1.18)$ & $0.93(0.56,1.64)$ & $1.00(0.70,1.42)$ & $0.55(0.31,0.95)$ \\
\hline A few times a week or more & $1.90(0.57,6.31)$ & $0.61(0.23,1.61)$ & $0.87(0.31,2.45)$ & $0.98(0.32,2.98)$ & $0.60(0.46,0.78)$ & $1.25(0.55,2.84)$ & $0.77(0.39,1.52)$ \\
\hline $\begin{array}{l}\text { Good self-described cooking } \\
\text { ability }^{\text {h }}\end{array}$ & $1.43(0.22,9.34)$ & $1.16(0.75,1.86)$ & $1.14(0.40,3.22)$ & $1.19(0.79,1.79)$ & $0.99(0.68,1.44)$ & $0.97(1.14,3.52)$ & $2.92(1.39,6.14)$ \\
\hline
\end{tabular}

${ }^{a}$ What are microorganisms?

Which of the following is considered the most important way to prevent food poisoning?

'Chilling or freezing eliminates harmful germs (true or false)

Which is the most hygienic way to wash your hands?

eIf a family member is going to be several hours late for a hot meal, how should you store the meal to keep it safe until this person is ready to eat it?

IImagine your electricity went off and the meat, chicken, and/or seafood in your freezer thawed and felt warm. What should you do?

${ }^{9}$ Which method is the best way of determining whether hamburgers are cooked enough?

hThose reporting the ability to cook the basics from scratch, prepare simple meals from a recipe, or cook almost anything (referent: those reporting they don't know how to cook, or that they can only cook

food when the instructions are on the box) 
Table 5 Odds ratios (and $95 \%$ Confidence Intervals), for demographic and food skills predictors of correct answers for individual food safety knowledge questions, answered correctly by fewer than $50 \%$ of respondents $(n=485)$; significant predictors are shown in bold

\begin{tabular}{|c|c|c|c|c|}
\hline & Leftover Storage Time $^{a}$ & Internal Cooking Temperature ${ }^{b}$ & Reheating Leftovers $^{c}$ & Cleaning Counters $^{\mathrm{d}}$ \\
\hline Age (in years) & $0.94(0.81,1.09)$ & $1.05(0.91,1.22)$ & $1.39(1.23 .1 .56)$ & $1.19(0.90,1.56)$ \\
\hline Male sex (female = referent) & $0.88(0.45,1.73)$ & $1.69(1.26,2.26)$ & $0.87(0.58,1.30)$ & $0.99(0.61,1.60)$ \\
\hline
\end{tabular}

Faculty

Science

Applied Health Sciences
Arts
Engineering
Environment
Mathematics
Co-op program of study
(regular program = referent)
Is a current food handler
Works or volunteers in a...
...food service location
...hospital
... daycare/child care facility
...long-term care/retirement home facility
Has ever taken a previous food course
Current living arrangement
Living at home
Traditional-style residence
Suite-style residence
Living off campus

$0.87(0.65,1.17)$

$0.59(0.51,0.67)$

$0.95(0.49,1.86)$

$1.72(1.34,2.21)$

$0.52(0.34,0.81)$

$1.00(0.43,2.37)$

$5.46(0.91,32.8)$

$0.12(0.03,0.58)$

$0.59(0.34,1.02)$

$0.88(0.41,1.88)$

$2.66(0.41,17.5)$

$1.37(0.96,1.97)$

referent

$\begin{array}{ll}\mathbf{0 . 4 5}(\mathbf{0 . 2 4}, \mathbf{0 . 8 6}) & 0.49(0.06,3.80) \\ \mathbf{0 . 3 1}(\mathbf{0 . 1 0}, \mathbf{0 . 9 7}) & 1.77(0.70,4.51) \\ 0.90(0.72,1.11) & 1.36(0.85,2.17)\end{array}$

Frequency of cooking from basic ingredients

Never or a few times a year

referent

A few times a month

$1.93(0.89,4.18)$

$1.57(0.78,3.18)$

$1.04(0.63,1.69)$

$1.50(0.44,5.18)$

A few times a week or more

Good self-described cooking ability ${ }^{\mathrm{e}}$

aHow long should leftovers be stored in the refrigerator?

${ }^{\mathrm{b}}$ All foods (except whole poultry) are considered safe when cooked to an internal temperature of (select one)

'To prevent food poisoning, how long should leftover foods be heated?

${ }^{\mathrm{d}}$ Which procedure for cleaning kitchen counter is best?

${ }^{\mathrm{e}}$ Those reporting the ability to cook the basics from scratch, prepare simple meals from a recipe, or cook almost anything (referent: those reporting

they don't know how to cook, or that they can only cook food when the instructions are on the box)

sanitizing. Further exploration of students' understanding of various hand hygiene activities, including perceived advantages of both washing and sanitizing, may be important in targeting hand hygiene messages; such messages should also consider that university students appear to be more motivated by social norms around acceptable hand hygiene behaviours than by scientific knowledge [46]. Given that only $26 \%$ of students at a Texas university washed their hands adequately - and $27 \%$ did not wash their hands at all - when using campus restroom facilities [47], and that poor hand hygiene among university students has been linked to increased infectious diseases, medical visits, and absence from class [48], supporting improved hand hygiene among students may be an important way for academic institutions to improve student health and contribute to academic success. Thus, colleges and universities should consider providing hand hygiene education to students, perhaps prior to co-operative education or volunteer placements, or prior to leaving residences to move to off-campus locations (in this population, typically at the end of the first or second year of undergraduate studies).

In this study, males in the Faculty of Science had relatively higher knowledge than females in the Faculty of 
Table 6 Relative proportions (i.e., prevalence ratios) of the number of correct answers for 11 food safety knowledge questions, with $95 \%$ Confidence Intervals (Cls), for the significant demographic and food skills predictors $(n=485)$; significant predictors are shown in bold

\begin{tabular}{|c|c|c|c|}
\hline & $\begin{array}{l}\text { Relative } \\
\text { Proportion }\end{array}$ & $P$-value & $95 \% \mathrm{Cl}$ \\
\hline Age (in years) & 1.02 & 0.045 & $1.00^{\mathrm{a}}, 1.05$ \\
\hline Male sex (female = referent) & 0.98 & 0.248 & $0.94,1.02$ \\
\hline $\begin{array}{l}\text { Faculty of Science } \\
\text { (all other Faculties = referent) }\end{array}$ & 1.06 & $<0.001$ & $1.04,1.07$ \\
\hline Male Sex*Faculty of Science & 1.13 & $<0.001$ & $1.07,1.19$ \\
\hline Is a current food handler & 1.11 & 0.010 & $1.02,1.19$ \\
\hline Works or volunteers in a hospital & 0.91 & 0.040 & $0.84,1.00$ \\
\hline \multicolumn{4}{|l|}{$\begin{array}{l}\text { Frequency of cooking from basic } \\
\text { ingredients (never = referent) }\end{array}$} \\
\hline A few times a year & 0.95 & 0.033 & $0.91,1.00$ \\
\hline A few times a month or more & 0.96 & 0.237 & $0.90,1.03$ \\
\hline $\begin{array}{l}\text { Has ever taken a previous food } \\
\text { course }\end{array}$ & 1.58 & $<0.001$ & $1.39,1.79$ \\
\hline \multicolumn{4}{|l|}{$\begin{array}{l}\text { Self-described cooking ability } \\
\text { (don't know how to, or can cook when } \\
\text { instructions are on box = referent) }\end{array}$} \\
\hline $\begin{array}{l}\text { Can cook the basics from scratch } \\
\text { (e.g., boil an egg) }\end{array}$ & 1.15 & 0.098 & $0.98,1.34$ \\
\hline $\begin{array}{l}\text { Can prepare simple meals from a } \\
\text { recipe }\end{array}$ & 1.33 & 0.003 & $1.10,1.60$ \\
\hline Can cook almost anything & 1.44 & $<0.001$ & $1.18,1.76$ \\
\hline \multicolumn{4}{|c|}{ Has ever taken a previous food course*self-described cooking ability } \\
\hline $\begin{array}{l}\text { Can cook the basics from scratch } \\
\text { (e.g., boil an egg) }\end{array}$ & 0.68 & 0.002 & $0.53,0.86$ \\
\hline $\begin{array}{l}\text { Can prepare simple meals from a } \\
\text { recipe }\end{array}$ & 0.65 & $<0.001$ & $0.57,0.75$ \\
\hline Can cook almost anything & 0.61 & $<0.001$ & $0.55,0.69$ \\
\hline
\end{tabular}

alower bound of confidence interval $=1.001$

Science, both of whom had relatively higher knowledge than all students in other Faculties (including the Faculty of Applied Health Sciences). Our finding is in line with results from other studies, where food safety knowledge has been found to be higher among health- and physical science-oriented students [28, 29, 31-33], although one recent study found no difference between health and non-health students [26]. The link between food safety knowledge and a science-oriented program of study at university is intuitive, as many such programs require courses in microbiology, where course content and bench work requirements may expose students to concepts of hygiene, contamination prevention, and microbial growth and inactivation. Here, many of the degree programs in the Faculty of Science have a microbiology course requirement; in comparison, none of the degree programs in Applied Health Sciences require microbiology.
Our finding above differs, however, from the many studies which have found higher food safety knowledge in females versus males [14, $15,25,28,29,32,33]$. It is unclear why our study's findings are in contrast, and variation in study populations, timeframes, and specific knowledge questions may have influenced this result. However, another potential explanation is that our estimates are adjusted for other factors, including selfreported cooking ability and cooking frequency, and include the interaction between sex and area of study, which may have been unadjusted for previous studies' findings, particularly older studies that relied univariable and bivariable analyses. Another study, by Sharif et al in 2010 [35], found that male health students and female humanities students had higher knowledge than male humanities students at Taif University in Jordan (there were no female health students), which is more closely aligned with our findings. Future studies should explore in more detail the nature of the relationship between sex and food safety knowledge among university students, and all studies of food safety knowledge, regardless of target population, should ensure that important confounders are measured and accounted using multivariable analyses.

Here, we found an interesting interaction between having taken a previous course in which students were taught to handle or prepare food (e.g., food handler training, home economics courses), and students' selfdescribed cooking ability. Our finding that food safety knowledge was higher in those who had taken a previous food course versus those who had not, among those who reported they essentially don't know how to cook, is intuitive. Similarly, our finding that food safety knowledge increased with self-described cooking ability, among those who have not taken a previous food course, is also intuitive. However, our finding that - among those who had previously taken a food course - food safety knowledge declined, and then only marginally rose, as selfdescribed cooking ability increased from not knowing how to cook, to basic cooking abilities, and then to excellent cooking abilities, has not been previously reported. This finding bears further investigation, and future studies may wish to investigate how development of food preparation skills may somehow supersede or override previously learned knowledge, as well as how individuals of different self-described cooking abilities operationalize food safety knowledge into practice during food preparation.

Among the undergraduate students in this study, $37 \%$ correctly identified that leftovers can be stored in the refrigerator for 3 to 4 days, whereas another $36 \%$ thought leftovers could only be stored for 1 to 2 days. If indeed students are throwing leftovers away prematurely as a result, this represents a potential area for education, 


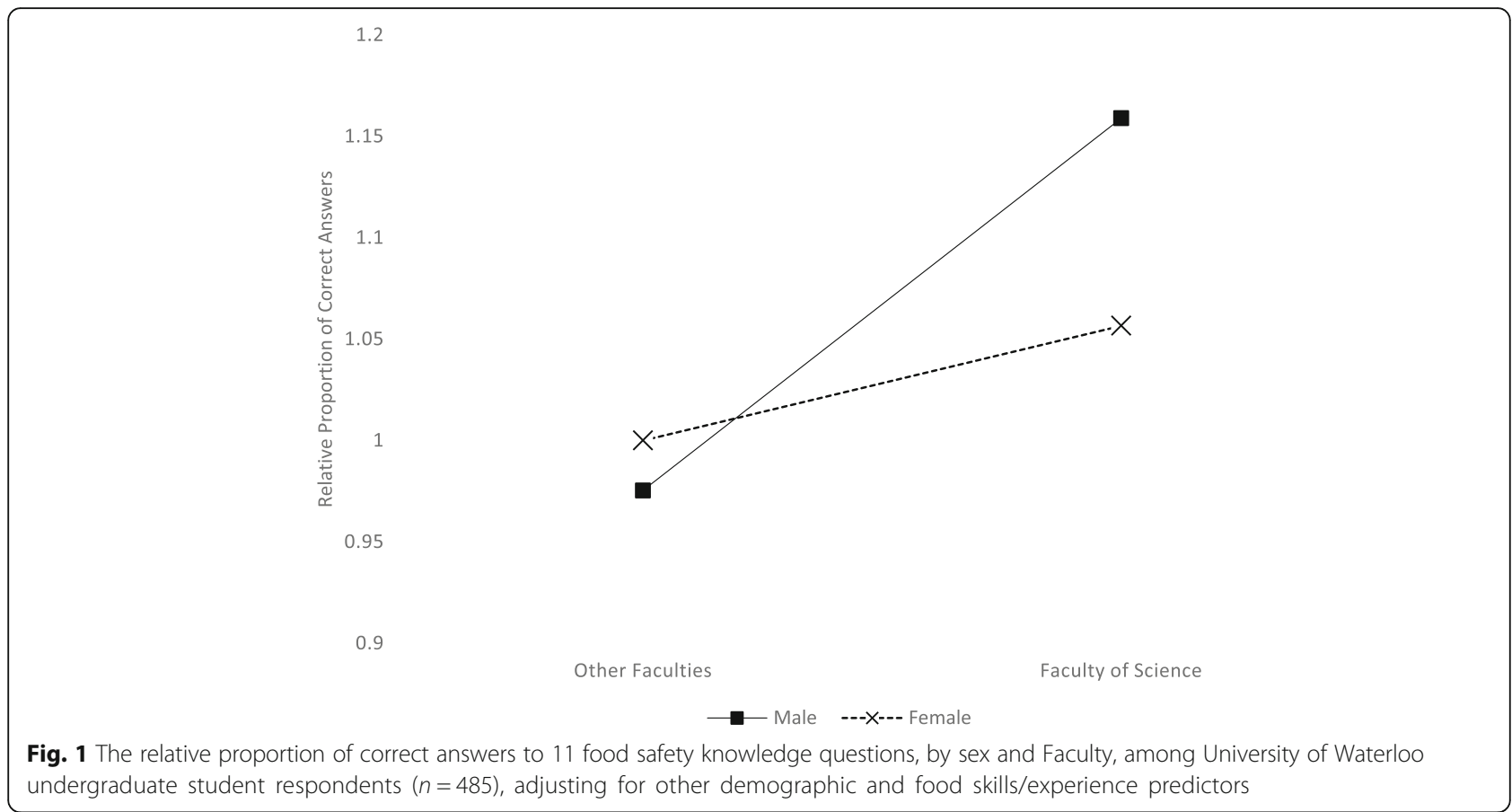

particularly given that food insecurity is an issue among both University of Waterloo students (e.g., $[49,50])$ and Canadian university students in general [51-54]. However, caution must be used in crafting such messages, since proper handling of leftovers involves not only the amount of time they can be retained in the refrigerator, but also their proper reheating. Only $32 \%$ of students in this study correctly identified that leftovers need to be reheated until they are boiling hot, with the rest selecting inadequate reheating options including no reheating. Thus, messages about the proper handling of leftovers that stress both a three-to-four day storage time and that leftovers must also be fully reheated until boiling (or better, until the internal temperature reaches $74{ }^{\circ} \mathrm{C}$ ),

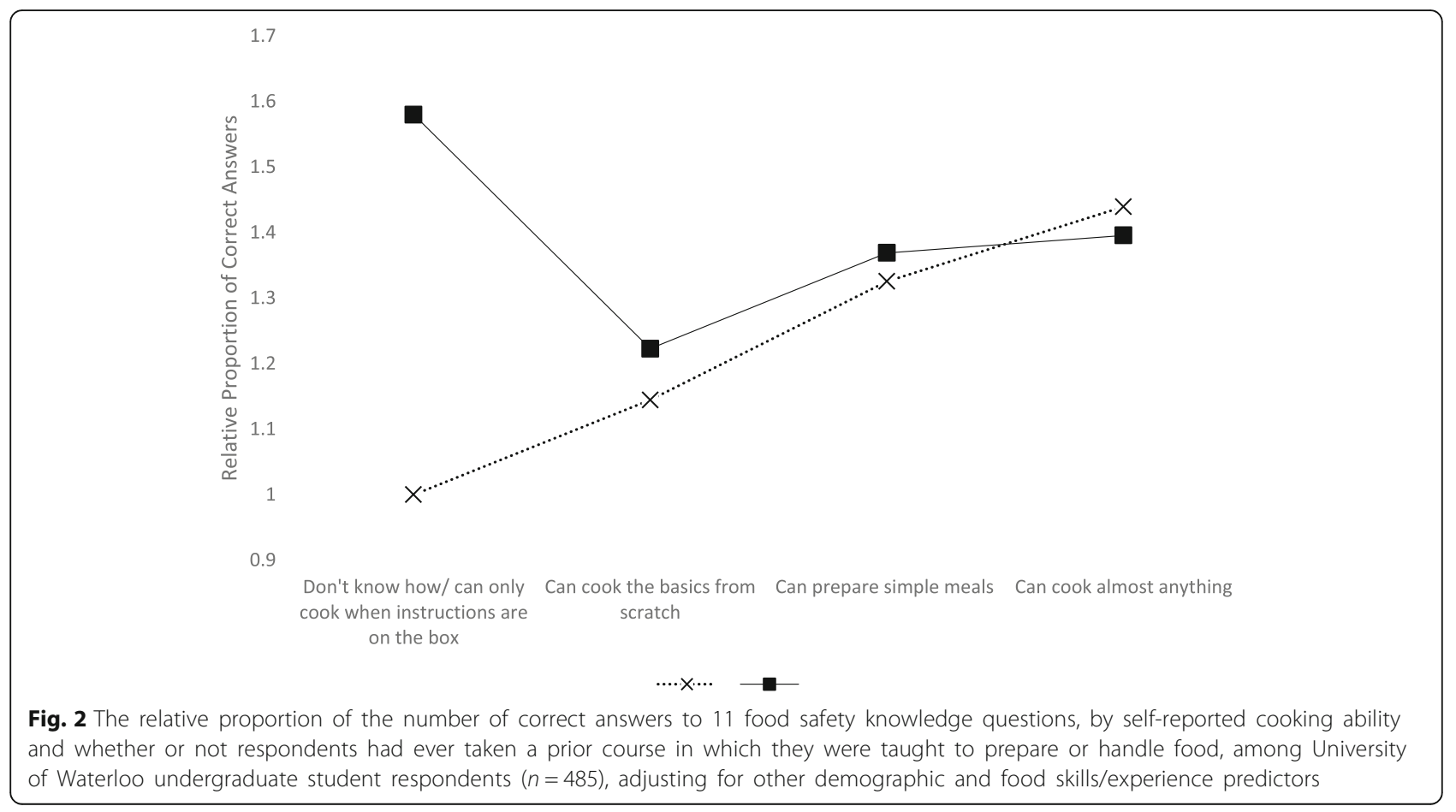


Table 7 Proportion of college and university students correctly answering food safety knowledge questions, compared across commonly used questions from an existing, validated food safety knowledge instrument [40], by study year and country

\begin{tabular}{|c|c|c|c|c|c|}
\hline $\begin{array}{l}\text { Food safety knowledge question, as worded } \\
\text { in this study (showing subscalea , and question } \\
\text { number from original questionnaire reference [40]) }\end{array}$ & $\begin{array}{l}\text { This study: undergraduate } \\
\text { students at the University } \\
\text { of Waterloo, Canada, } 2015 \\
(n=485)\end{array}$ & $\begin{array}{l}\text { Undergraduate students of the } \\
\text { Lebanese American University, } \\
\text { Lebanon, } 2013 \text { ( } n=1172) \text { [33] }\end{array}$ & $\begin{array}{l}\text { Undergraduate students } \\
\text { attending a major American } \\
\text { university, } 2013(n=786)[26]\end{array}$ & $\begin{array}{l}\text { University students at the } \\
\text { Aristotle University of } \\
\text { Thessaloniki, Greece, } 2010 \\
(n=837) \text { [32] }\end{array}$ & $\begin{array}{l}\text { Female college students } \\
\text { living at private and } \\
\text { university dorms, Irbid city, } \\
\text { Jordan, } 2009(n=867)[31]\end{array}$ \\
\hline $\begin{array}{l}\text { Which procedure for cleaning kitchen counter } \\
\text { is best? }(\mathrm{CC}, 5)\end{array}$ & $24.0 \%$ & $78.7 \%$ & $27 \%$ & $32.0 \%$ & $31 \%$ \\
\hline $\begin{array}{l}\text { Which is the most hygienic way to wash your } \\
\text { hands? }(C C, 7)\end{array}$ & $71.5 \%$ & - & $55 \%$ & - & $51 \%$ \\
\hline $\begin{array}{l}\text { Imagine your electricity went off and the meat, } \\
\text { chicken, and/or seafood in your freezer thawed } \\
\text { and felt warm. What should you do? (ST, 4) }\end{array}$ & $56.0 \%$ & - & - & - & $20.1 \%$ \\
\hline $\begin{array}{l}\text { Which of the following is considered the most } \\
\text { important way to prevent food poisoning? (ST, 5) }\end{array}$ & $84.3 \%$ & - & $71 \%$ & $51.3 \%$ & $58.4 \%$ \\
\hline $\begin{array}{l}\text { If a family member is going to be several hours } \\
\text { late for a hot meal, how should you store the } \\
\text { meal to keep it safe until this person is ready to } \\
\text { eat it? (ST, 8) }\end{array}$ & $65.7 \%$ & - & - & - & $49.8 \%$ \\
\hline $\begin{array}{l}\text { All foods (except whole poultry) are considered } \\
\text { safe when cooked to an internal temperature of: } \\
\text { (ST, 9) }\end{array}$ & $41.6 \%$ & - & - & $20.7 \%$ & $33 \%$ \\
\hline $\begin{array}{l}\text { Which method is the best way of determining } \\
\text { whether hamburgers are cooked enough? } \\
\text { (ST, 10) }\end{array}$ & $51.4 \%$ & - & $53 \%$ & - & $8.2 \%$ \\
\hline $\begin{array}{l}\text { To prevent food poisoning, how long should } \\
\text { leftover foods be heated? (ST, 12) }\end{array}$ & $31.8 \%$ & - & - & - & $36.9 \%$ \\
\hline Chilling or freezing eliminates harmful germs (FR, 1) & $77.0 \%$ & $64.0 \%$ & $60 \%$ & $78.3 \%$ & $52.2 \%$ \\
\hline
\end{tabular}

${ }^{a} \mathrm{CC}$ cross contamination prevention/disinfection procedures scale, ST safe times/temperatures for cooking/storing food scale, FR foods that increase the risk of foodborne disease scale 
may be a way to address food safety, food security, and food waste among students.

This study is subject to several limitations inherent in food safety knowledge surveys, most notably the potentially limited generalizability of findings to students outside the studied institution, and the limited number of knowledge questions we were able to include. In addition, our use of multiple choice questions, that by design provide respondents with the correct answer option (versus open-ended formats), may have led to an overestimate of students' true knowledge; how student performance on multiple choice questions relates to their true food safety knowledge merits further investigation. Our use of an online survey with recruitment via mass email may have influenced the types of students responding to the survey. Here, our respondents included more females and students from the Faculties of Applied Health Science and Science, compared to undergraduate students overall. Given our finding that being in the Faculty of Science was associated with greater knowledge (adjusting for other factors), the mean food safety knowledge score reported for our student sample likely overestimates the mean food safety knowledge of the undergraduate student body as a whole. A final potential limitation is our exclusion of missing data. This said, missing data were infrequent (i.e., except for "previous food course" missing at $4.74 \%$, no other variable had missing percentage higher than $1.65 \%$, and most were at $0 \%$ ), and hence unlikely to result in much bias in our reported results.

Despite these limitations, we identified several important areas for targeted food safety messages, and our findings are generally in line with those for other similar populations. Students in Faculties other than the Faculty of Science may benefit from general food safety education, whether through courses, or via extra-curricular activities. It may also be useful to target education to younger students, and to those who cook infrequently, and to time such education so it occurs while students are in residence, and prior to co-operative education or volunteer placements. Providing general support for improved hand hygiene across the undergraduate population as a whole, and providing detailed hand washing versus hand sanitizing messages to those who work or volunteer in hospital settings, may also be important. Educating students about proper handling of leftovers, making sure to combine messages about storage times with proper reheating, may be a way to address food safety in tandem with food security in this undergraduate population.

\section{Conclusion}

In 1998, Unklesbay et al. [28] published one of the first explorations of food safety among college students, and concluded with a call for improved food safety education, specifically that "...the role of [food-related educators] should be expanded to include all college disciplines, especially as the majority of the U.S. population is one or more generations removed from direct experiences on farms and ranches..." and that "...students and the public need to be empowered to make informed decisions." In the 18 years since this call to action, there have been many assessments of food safety knowledge, attitudes, and practices among college and university students in a variety of settings and countries $[14,20,25,26,28$, $31-33,35]$, including several that have evaluated the effectiveness of different interventions aimed at improving these factors $[29,55]$. Despite this, food safety among college and university students appears to still be an important yet inadequately addressed issue, as evidenced in part by our findings. Here we found that students in Faculties outside of the Faculty of Science, younger students, and those who cook infrequently could benefit from food safety education, and that supporting improved hand hygiene, in particular clarifying hand washing versus hand sanitizing messages, may also be important. Academic institutions should consider their role in providing both general and targeted information, particularly if such provision can be viewed as a key part of preparing students for work or volunteer placements, or as part of supporting student health and success in general.

\section{Additional files}

Additional file 1: Study questionnaire. (PDF 367 kb)
Additional file 2: Variables with Missing Data. (DOCX 51 kb)

\section{Acknowledgements}

The authors thank Institutional Analysis and Planning, University of Waterloo for providing the simple random sample, Joan Marshall for emailing the survey to the undergraduate students, and Merryn Maynard for providing the references on food insecurity.

\section{Funding}

This research was unfunded. The gift cards used for remuneration were purchased from S. Majowicz's University of Waterloo start-up funding.

\section{Availability of data and materials}

Raw data supporting this study may be made available upon request to the corresponding author. Because the original participant consent process did not explicate that raw data might be provided to individuals outside the original study team, or for alternate purposes, data access requests will only be considered after institutional ethics review and approval has been obtained by the requesting researcher/ research team.

\section{Authors' contributions}

SMC and SEM conceived and designed the study, and SMC collected the data with input from SEM. SEM and JAD conceived the analysis plan, SEM conducted the analyses with ongoing input from JAD. SEM interpreted the results with input from SMC and JAD. SMC drafted the introduction, and SEM drafted the methods, results and discussion. All authors provided comments on drafts, and read and approved the final manuscript. 


\section{Competing interests}

The authors declare that they have no competing interests.

\section{Consent for publication}

Not applicable.

\section{Ethics approval and consent to participate}

This study was reviewed and received ethics clearance through a University of Waterloo Research Ethics Committee. On the first page of the web survey, students were again provided study details (including their right to discontinue participating at any time), and students gave informed consent before proceeding to the survey questions. (NOTE: these statements also appear in the Methods section).

\section{Author details}

${ }^{1}$ School of Public Health and Health Systems, University of Waterloo, 200 University Ave. West, Waterloo, Ontario N2L 3G1, Canada. ${ }^{2}$ Department of Statistics and Actuarial Sciences, University of Waterloo, Waterloo, Ontario, Canada.

Received: 21 May 2016 Accepted: 3 November 2016

Published online: 09 November 2016

\section{References}

1. Havelaar AH, Kirk MD, Togerson PR, Gibb HJ, Hald T, Lake RJ, et al. World health organization global estimates and regional comparisons of the burden of foodborne disease in 2010. PLoS Med. 2015;12(12):e1001923.

2. Thomas MK, Murray R, Flockhart L, Pintar K, Pollari F, Fazil A, et al. Estimates of the burden of foodborne illness in Canada for 30 specified pathogens and unspecified agents, circa 2006. Foodborne Pathog Dis. 2013;10(7):639-48.

3. Henson SJ, Majowicz SE, Masakure O, Sockett PN, MacDougall L, Edge $\mathrm{VL}$, et al. Estimation of the costs of acute gastrointestinal illness in British Columbia, Canada. Int J Food Microbiol. 2008;127:43-52.

4. Henson SJ, Majowicz SE, Masakure O, Sockett PN, MacDougall L, Edge $\mathrm{VL}$, et al. Corrigendum to "Estimation of the costs of acute gastrointestinal illness in British Columbia, Canada". Int J Food Microbiol. 2011;147:86.

5. Majowicz SE, McNab WB, Sockett P, Doré K, Edge VL, Buffett MC, et al. Burden and cost of gastroenteritis in a Canadian community. J Food Prot. 2006;69(3):651-9.

6. Majowicz SE, MCNab WB, Sockett P, Doré K, Edge VL, Buffett MC, et al. Erratum: burden and cost of gastroenteritis in a Canadian community. J Food Prot. 2011; doi:10.4315/0362-028X.74.1.2.

7. Lee MB, Middleton D. Enteric illness in Ontario, Canada, from 1997 to 2001. J Food Prot. 2003;66(6):953-61.

8. Ontario Burden of Infectious Disease Study Advisory Group. Ontario Burden of Infectious Disease Study (ONBOIDS): An OAHPP/ICES Report. Toronto: Agency for Health Protection and Promotion, Institute for Clinical Evaluative Sciences; 2010.

9. Kwong JC, Ratnasingham S, Campitelli MA, Daneman N, Deeks SL, Manuel $D G$, et al. The impact of infection on population health: results from the Ontario burden of infectious diseases study. PLoS One. 2012;7(9):e44103.

10. Denagamage TN, O'Connor AM, Sargeant JM, Rajić A, McKean JD. Efficacy of vaccination to reduce salmonella prevalence in live and slaughtered swine: a systematic review of literature from 1979 to 2007. Foodborne Pathog Dis. 2007:4(4):539-49.

11. LeJeune JT, Rajala-Schultz PJ. Unpasteurized milk: a continued public health threat. Clin Infect Dis. 2008;48:93-100.

12. Hedberg CW, Smith SJ, Kirkland E, Radke V, Jones TF, Selman CA, et al. Systematic environmental evaluations to identify food safety differences between outbreak and nonoutbreak restaurants. J Food Prot. 2006; 69(11):2697-702.

13. Young I, Waddell L, Hardling S, Greig J, Mascarenhas M, Sivaramalingam B, et al. A systematic review and meta-analysis of the effectiveness of food safety education interventions for consumers in developed countries. BMC Public Health. 2015;15:822-36.

14. Byrd-BredBenner C, Abbot JM, Wheatley V, Schaffner D, Bruhn C, Blalock L. Risky eating behaviours of young adults: implications for food safety education. J Am Diet Assoc. 2008;108:549-52.
15. Nesbitt A, Majowicz S, Finley R, Marshall B, Pollari F, Sargeant J, et al. High-risk food consumption and food safety practices in a Canadian community. J Food Prot. 2009;72(12):2575-86.

16. Altekruse SF, Yang S, Timbo BB, Angulo FJ. A multi-state survey of consumer food-handling and food-consumption practices. Am J Prev Med. 1999;16(3):216-21.

17. Fein SB, Lando AM, Levy AS, Teisi MF, Noblet C. Trends in U.S. consumers' safe handling and consumption of food and their risk perceptions, 1988 through 2010. J Food Prot. 2011;74(9):1513-23.

18. Byrd-Bredbenner C, Maurer J, Wheatley V, Cottone E, Clancy M. Observed food safety behaviours of young adults. Br Food J. 2007;109(7):519-30.

19. Byrd-Bredbenner C, Maurer J, Wheatley V, Cottone E, Clancy M. Food safety hazards lurk in the kitchens of young adults. J Food Prot. 2007;70(4):991-6.

20. Abbot JM, Byrd-BredBenner C, Schaffner D, Bruhn CM, Blalock L. Comparison of food safety cognitions and self-reported food-handling behaviours with observed food safety behaviours of young adults. Eur J Clin Nutr. 2009;63:572-9.

21. Majowicz SE, Doré K, Flint JA, Edge VL, Read S, Buffett MC, et al. Magnitude and distribution of acute, self-reported gastrointestinal illness in a Canadian community. Epidemiol Infect. 2004;132:607-17.

22. Arthur A, Gournis E, McKeown D, Yaffe B. Foodborne illness in Toronto. Toronto Public Health. 2009. http://www.toronto.ca/health/dinesafe/pdf/ staffreport_april15_2009_appx_a.pdf. Accessed 15 Apr 2016.

23. Pollard CM, Meng X, Williamson S, Dodds J, Binns CW. Eating out is associated with self-reported food poisoning: a Western Australia population perspective, 1998 to 2009. Public Health Nutr. 2013;17(10):2270-7.

24. Slater J. Is cooking dead? The state of home economics food and nutrition education in a Canadian province. Int J Consum Stud. 2013;37:617-24.

25. Byrd-BredBenner C, Maurer J, Wheatley V, Schaffner D, Bruhn C, Blalock L. Food safety self-reported behaviors and cognitions of young adults: results of a national study. J Food Prot. 2007;70(8):1917-26.

26. Green EJ, Knechtges PL. Food safety knowledge and practices of young adults. J Environ Health. 2015;77(10):18-24.

27. Ferk CC, Calder BL, Camire ME. Assessing the food safety knowledge of university of Maine students. J Food Sci Educ. 2016;15(1):14-22.

28. Unklesbay N, Sneed J, Toma R. College students' attitudes, practices, and knowledge of food safety. J Food Prot. 1998;61 (9):1175-80.

29. Yarrow L, Remig VM, Higgins MM. Food safety educational intervention positively influences college students' food safety attitudes, beliefs, knowledge, and self-reported practices. J Environ Health. 2009;71(6):30-5.

30. Stein SE, Dirks BP, Quinlan JJ. Assessing and addressing safe food handling knowledge, attitudes, and behaviours of college undergraduates. J Food Sci Educ. 2010;9(2):47-52.

31. Osaili TM, Obeidat BA, Abu Jamous DO, Bawadi HA. Food safety knowledge and practices among college female students in north of Jordan. Food Control. 2011;22(2):269-76.

32. Lazou T, Georgiadis M, Pentieva K, McKevitt A, lossifidou E. Food safety knowledge and food-handling practices of Greek university students: a questionnaire-based survey. Food Control. 2012;28(2):400-11.

33. Hassan HF, Dimassi H. Food safety and handling knowledge and practices of Lebanese university students. Food Control. 2014;40:127-33.

34. Sanlier N, Konaklioglu E. Food safety knowledge, attitude and food handling practices of students. Br Food J. 2012;114(4):469-80.

35. Sharif $L$, Al-Malki T. Knowledge, attitude and practice of Taif University students on food poisoning. Food Control. 2010;21(1):55-60.

36. Garayoa R, Córdoba M, García-Jalón I, Sanchez-Villegas A, Vitas Al. Relationship between consumer food safety knowledge and reported behaviour among students from health sciences in one region of Spain. J Food Prot. 2005;68(12):2631-6.

37. Majowicz SE, Diplock KJ, Leatherdale ST, Bredin CT, Rebellato S, Hammond D, et al. Food safety knowledge, attitudes, and self-reported practices among Ontario high school students. Can J Public Health. 2015;106(8)::520-6.

38. Rebellato S, Cholewa S, Chow J, Poon D. Impact of PROTON a food handler certification course on food handlers' knowledge, attitudes and behaviours. J Food Saf. 2011;32(1):129-33.

39. Lynch RA, Steen MD, Pritchard TJ, Buzzell PR, Pintauro SJ. Delivering food safety education to middle school students using a web-based, interactive, multimedia, computer program. J Food Sci Educ. 2008; $7(2): 35-42$ 
40. Byrd-Bredbenner C, Wheately V, Schaffner D, Bruhn C, Blalock L, Maurer J. Development and implementation of a food safety knowledge instrument. J Food Sci Educ. 2007;6(3):46-55.

41. Byrd-Bredbenner C, Wheatley V, Schaffner D, Bruhn C, Blalock L, Maurer J. Development of food safety psychosocial questionnaires for young adults. J Food Sci Educ. 2007:6(2):30-7.

42. Spiegelman D, Hertzmark E. Easy SAS calculations for risk or prevalence ratios and differences. Am J Epidemiol. 2005;162(3):199-200.

43. Barros AJD, Hirakata VN. Alternatives for logistic regression in cross-sectional studies: an empirical comparison of models that directly estimate the prevalence ratio. BMC Med Res Methodol. 2003;3:21-34.

44. Skove T, Deddens J, Petersen MR, Endahl L. Prevalence proportion ratios: estimation and hypothesis testing. Int J Epidemiol. 1998;27(1):91-5.

45. Rogers WH. Regression standard errors in clustered samples. In: Stata Technical Bulletin 13:19-23. Reprinted in Stata Technical Bulletin Reprints, vol. 3. College Station: Stata Press; 1993. p. 88-94.

46. Miko BA, Cohen B, Conway L, Gilman A, Seward Jr SL, Larson E. Determinants of personal and household hygiene among college students in New York City, 2011. Am J Infect Control. 2012;40(10):940-5.

47. Anderson JL, Warren CA, Perez E, Louis Rl, Phillips S, Wheeler J, et al. Gender and ethnic differences in hand hygiene practices among college students. Am J Infect Control. 2008;36(5):361-8.

48. Prater KJ, Fortuna CA, McGill JL, Brandeberry MS, Stone AR, Lu X. Poor hand hygiene by college students linked to more occurrences of infectious diseases, medical visits, and absence from class. Am J Infect Control. 2016:44(1):66-70

49. University of Waterloo Federation of Students. Feds student food bank. http://www.feds.ca/foodbank/(2016). Accessed 13 May 2016.

50. Wong S, Choi S. Feds student food bank end of term report: Winter 2016. Waterloo: University of Waterloo; 2016.

51. Farahbakhsh J, Ball GDC, Farmer AP, Maximova K, Hanbazaza M, Willows ND. How do student clients of a university-based food bank cope with food insecurity? Can J Diet Pract Res. 2015;76(4):200-3.

52. Jessri M, Abedi A, Wong A, Eslamian G. Nutritional quality and price of food hampers distributed by a campus food bank: a Canadian experience. J Health Popul Nutr. 2014;32(2):287-300.

53. Willows ND, Au V. Nutritional quality and price of university food bank hampers. Can J Diet Pract Res. 2006;67(2):104-7.

54. Meldrum LA, Willows ND. Food insecurity in university students receiving financial aid. Can J Diet Pract Res. 2006;67:43-6.

55. Abbot JM, Policastro P, Bruhn C, Schaffner DW, Byrd-BredBenner C. Development and evaluation of a university campus-based food safety media campaign for young adults. J Food Protect. 2012;75(6):1117-24

\section{Submit your next manuscript to BioMed Central and we will help you at every step:}

- We accept pre-submission inquiries

- Our selector tool helps you to find the most relevant journal

- We provide round the clock customer support

- Convenient online submission

- Thorough peer review

- Inclusion in PubMed and all major indexing services

- Maximum visibility for your research

Submit your manuscript at www.biomedcentral.com/submit 